\title{
TRANSPLANTES DE ÓRGÃOS: AVALIAÇÃO PSICOLÓGICA
}

\section{Organ Transplantation: Psychological Evaluation}

Claire Terezinha Lazzaretti ${ }^{1}$

\section{Resumo}

A decisão por um transplante de órgão é muito delicada e requer muitas discussões e esclarecimentos com paciente e equipe. $\mathrm{O}$ transplante pode provocar inúmeras implicações psicológicas que afetam o doador e o receptor do órgão. A atitude diante do transplante depende das características subjetivas de cada paciente. A motivação tanto do doador como do receptor para o transplante atualiza conflitos psicológicos que devem ser reconhecidos e abordados antes da cirurgia. Considerando as implicações psicológicas em todas as etapas deste procedimento, faz-se necessánia a inserção do psicólogo como participante da equipe multidisciplinar. O objetivo deste trabalho é levantar algumas questões sobre a vivência pré e pós-transplante por parte dos doadores e receptores. Com base nestes dados, elaborou-se um protocolo de avaliação psicológica aqui apresentado.

Palavras-chave: Psicologia; Transplante; Doador vivo.

\section{Abstract}

Deciding for a transplantation is very delicate and requires multiples discussions with the patient and team. Transplantation carries along numerous psychological implications affecting both, the donor and the recipient. The attitude towards transplantation depends on the subjective characteristics of the patient. The motivation of the donor and the recipient to transplantation actualizes psychological conflicts, which should be studied and recognized in time. Considering the significant psycho-sociological implications in all its stages, the method of transplantation soon indicates the need for a psychologist as a member of a multidisciplinary team. The aim of the study is show the influence of some aspects in the life of the donor and the recipient in pretansplantation and posttranplantadion. On this basis in these data, was elaborated a protocol of psychological evaluation, here presented.

Keywords: Psychological; Transplantation; Living donor.

1 Serviço de Psicologia do Hospital de Clínicas da Universidade Federal do Paraná. Rua Coronel Dulcídio, 97 Cj. 01 80420-060 Curitiba-PR clairetl@ufpr.br 
Doenças crônicas e transplantes de órgãos exemplificam paradoxalmente situações de perdas e ganhos que muitos de nós experimentamos em formas diferentes durante o curso da vida. Surgem múltiplas questões relativas à habilidade de adaptação a mudanças de saúde e à capacidade funcional, alteração das relações sociais, novas percepções de si mesmo, revisão de metas e planos de vida são preocupações que transcendem o campo do transplante.

Este trabalho tem por objetivo a exposição e discussão de algumas questões da experiência de 10 anos de trabalho em Unidades de Transplante de Órgãos do Hospital de Clínicas da Universidade Federal do Paraná, mais precisamente no Serviço de Transplante Renal e no Serviço de Transplante Hepático.

É importante ressaltar que este artigo não tem a pretensão de estabelecer argumento teórico ou filosófico a respeito dos transplantes de órgãos, ou mesmo da relação receptor-doador, mas sim levantar algumas questões acerca da situação pré e pós-transplante por parte dos doadores e receptores. Mesmo porque dificilmente conseguiríamos traçar um perfil psicológico dos indivíduos submetidos ao transplante, uma vez que o percurso e o significado da doença para o indivíduo são únicos e singulares.

Enfocar a problemática do transplante é uma tarefa bastante complexa para ser tratada de forma parcial e isolada, pois o percurso, desde 0 diagnóstico da doença até a indicação desta terapêutica, pode ser longo ou curto, mas quase sempre árduo. São pacientes que trazem consigo uma história de doença crônica, marcada pela relação instigante existente entre esta e o psiquismo.

O trabalho da psicologia se insere em todo o processo do transplante. Desde o contato inicial para avaliação pela equipe responsável, os pacientes passam por uma série, relativamente padronizados de etapas do processo de transplante: avaliação para ser aceito como um potencial receptor de transplante; a espera de um órgão satisfatório de doador; a cirurgia e o perío do de recuperação pós-cirúrgica e os ajustes a longo prazo do póstransplante.

As etapas podem variar consideravelmente em sua duração, dependerão de fatores como a severidade da doença do paciente, a disponibilidade local e regional de doadores de órgão e 0 tempo de inscrição dos candidatos na lista de es- pera pelo órgão antes de ser transplantado. Porém, a sucessão geral dos eventos e períodos de tempo, pode-se dizer, é semelhante entre todos os tipos de candidatos de transplante de órgão sólidos e receptores, é o que mostra nossa experiência com os transplantes renais, hepáticos, pâncreas-rim e fígado-rim.

\section{Escolha pelo transplante de órgão}

Para muitos pacientes, a avaliação para transplante de órgão marca o fim de uma longa estrada de convivência com a deterioração da saúde e o início de uma outra modalidade de tratamento. Alguns chegam à avaliação com sentimento de alívio, resignação ou otimismo. Um pequeno número de pacientes, quando a doença ainda se mostra sobre controle ou é assintomática, acredita que seu estado não é severo o bastante para se submeterem ao transplante. Na grande maioria, embora estes possam ter preocupações e inquietações justificáveis, apresentam pouca ou nenhuma ambivalência sobre a necessidade da realização do transplante. No entanto, ao se submeterem à avaliação, observa-se uma mistura de sentimentos contraditórios e angústia, tais como:

- Esperança de ter um futuro saudável e estilo de vida normal, combinado com inquietação e temor sobre os riscos de cirurgia, de como será viver com o órgão de outra pessoa e da possibilidade do transplante falhar;

- Ânsia de prosseguir a avaliação, com ansiedade sobre a incerteza de ser aceito como um candidato satisfatório;

- Preocupações que o órgão não chegue a tempo, com a esperança de que neste tempo terá que esperar a medicina descobrir outras opções de tratamento, o que tardaria ou até mesmo eliminaria a necessidade do transplante.

Além da tensão com seus problemas à saúde, os pacientes também podem ter preocupações acerca de como a equipe de transplante os avaliará psicologicamente e psicossocialmente. Podem se preocupar sobre revelar ou discutir a fundo indiscrições do passado e comportamentos de seu estilo de vida, como fumar, beber e/ou uso de substância ilícita. Também podem considerar que história passada de depressão ou outra doença mental serão vistas como desfavoráveis pela equipe de transplante. Na realidade, estas 
preocupações não são infundadas. As equipes de transplante consideram seriamente fatores como estes, para tomar decisões sobre quem é ou não, o candidato de transplante, embora a importância dada a estes fatores varie consideravelmente de centro para centro, e de acordo com o tipo de transplante.

A equipe de transplante, além dos dados médicos, geralmente tem preocupações sobre algumas questões psicossociais e psicológicas que devem ser focalizadas adequadamente na avaliação.

Embora cada equipe de transplante determine quais informações psicossociais são consideradas importantes, dentro de seus critérios, colocando graus diferentes de ênfase em certas áreas da avaliação, as informações que precisam ser obtidas para conhecer o paciente e sua relação com o transplante permanecem relativamente constantes. No protocolo utilizado em nosso serviço (anexo I), os componentes básicos da avaliação psicológica pré-transplante podem ser resumidos na história pregressa e atual: de saúde mental, de enfrentamento da doença, de uso de drogas, do estado mental, de apoio social e de compreensão da doença e procedimento do transplante. Julgamentos sobre os riscos de o paciente aderir a comportamentos prejudiciais para saúde depois do transplante devem ser feitos levando em conta a história de vida e estado atual do paciente. Por exemplo, se abstinência de bebida alcoólica é necessária, a equipe de transplante precisa ter claro os critérios de pré-requisitos que determinem a probabilidade que um paciente poderá permanecer abstinente e especificar para 0 paciente 0 padrão esperado que o qualifica para continuar sendo um candidato de transplante. O Serviço de Transplante Hepático do Hospital de Clínicas adota como critério para listar um paciente 0 mínimo de 6 meses de abstinência de álcool e em alguns casos de cirrose alcoólica requer a participação dele em programa de reabilitação ou de apoio para abstinência. (Parolin et al., 2002)

Cada um destes fatores do referido protocolo pode ser avaliado com uma entrevista aberta, não estruturada. Alternativamente, pode ser criado um questionário estruturado ou semi-estruturado, se a equipe de transplante assim o desejar. Entretanto, o mais importante é que os dados coletados possam ser úteis para identificar áreas de particular preocupação e que requerem informação adicional de familiares e/ou dos pacientes, visando a encaminhamento para outros procedimentos, tal como psicoterapia. Em nosso serviço, as avaliações psicológicas são realizadas por meio de entrevistas com algumas perguntas preestabelecidas, mas com uma metodologia voltada para a escuta, ou seja, o entrevistado pode falar livremente. Após esta entrevista com finalidade também terapêutica, o preenchimento da folha do protocolo da psicologia possibilita que os dados também possam ser utilizados com propósito para pesquisas.

A questão deve-se excluir pacientes do transplante com base nos fatores psicológicos e psicossociais sempre foi e continua sendo controvérsia dentro da comunidade mundial de transplante de órgão e da ética médica. Questões morais e éticas surgem quando é possibilitado ou negado o transplante baseado na história de comportamento e/ou estado atual psicossocial. (Surman \& Cosimi, 1996)

Estes critérios, a princípio, foram adotados devido à escassez da provisão de órgãos doados e sua difícil distribuição, porém, apesar de muitas vezes serem considerados subjetivos, podem visar ao risco e beneficio do transplante para o paciente e sua família. A avaliação psicológica pré-transplante, de acordo com o protocolo apresentado, pode ser um importante instrumento para identificar pacientes que necessitam de intervenções psicoterapêuticas, isto é, em lugar de apenas identificar os que deveriam ser excluídos como candidatos, esta abordagem visa também ao encaminhamento de pacientes a serviços ou intervenções que os ajudarão a atingir melhor qualidade de vida antes e depois do transplante (Skotzko et al., 2001)

Semelhante a outras populações que vivem com doença crônica, os candidatos de transplante apresentam significativamente maior risco de angústia e/ou distúrbios depressivos quando comparados com a população geral (Dew et al., 1998). O tempo de espera para transplante, apesar de ter como seu elemento central a incerteza, pode ser importante para aceitação da idéia de que eles precisam do transplante e ao mesmo tempo pensar que vida podem buscar no pós-cirúrgico. Esta espera pode possibilitar uma escolha, desejar o transplante.

Na realidade, há alguma evidência de que quando esta espera é extremamente curta, no pós- 
transplante, o ajuste psicológico é mais difícil do que para pacientes que esperam por períodos mais longos (Dew et al., 1996). A experiência nos mostra que um certo nível de ajuste psicológico é necessário também no pós-transplante.

Um elemento que pode reduzir a incerteza durante o tempo de espera, mas pode aumentar mais adiante a tensão familiar, é o transplante com doador vivo. Em transplante intervivos (TIV), a doação de órgão por um membro familiar é o mais comum. Embora a doação de cadáver continue sendo a preferência na maioria dos casos, a doação com doador vivo permanece uma opção para muitos pacientes. Usualmente os transplantes de rim e os de fígado e, mais recentemente, os transplantes de pâncreas e os de pulmão já utilizam o doador vivo, que freqüentemente são: os irmãos, os pais e os filhos, mas, os não relacionados, sem parentesco se tornaram opções viáveis para alguns pacientes.

A decisão pelo TIV é muito delicada, requer competência da equipe multidisciplinar para propiciar múltiplas discussões, orientações e informações com o paciente e a família. $\mathrm{O}$ paciente e a família devem estar cientes de que estão optando por um tratamento muito especializado, com grande possibilidade de sucesso, mas que também comporta risco de vida tanto para o doador quanto para o receptor. $\mathrm{O}$ nível de expectativa frente à cirurgia pode variar, principalmente dependendo do estado clínico do paciente.

Como já foi dito, geralmente os pacientes são convidados a optarem pelo transplante, num momento de muita tensão emocional, quando receberam o diagnóstico de uma doença, em alguns casos, sem outra alternativa de tratamento. E um momento de impasse: "situação difícil de que parece impossível uma saída favorável", mas precisam autorizar a inscrição de seu nome na lista para um transplante.

\section{Sobre o doador}

Depois da aceitação do TIV, como alternativa de tratamento terapêutico, a escolha do doador é crucial para o procedimento.

O TIV é uma alternativa de tratamento médico que desencadeia inúmeras implicações psicológicas tanto no doador quanto no receptor. A preparação psicológica do doador e do receptor para um TIV atualiza ocasionalmente conflitos intrapsíquicos que deveriam ser reconhecidos e trabalhados em tempo, tendo em mente seus efeitos no pré e pós-transplante (Bonomini, 1991).

A equipe de transplante tem o dever de informar ao potencial doador sobre todos os fatos relacionados ao transplante, apontando objetivamente possíveis problemas e complicações tanto para o doador quanto para o receptor. Neste contexto, é importante avaliar a existência de persuasão ou qualquer outro tipo de situação que caracterize o desejo de doar como um ato forçado.

Na entrevista de avaliação psicológica com o doador além dos componentes básicos da história pregressa e atual: de saúde mental, de uso de drogas, do estado mental e de compreensão do procedimento do transplante (anexo II), é de suma importância, não só para estabelecer o parecer, acolher a intenção da doação, do ato de se submeter a um risco cirúrgico em detrimento da intenção de ajudar a saúde de um outro, com todas as implicações imaginárias e reais decorrentes. É condição prévia principal para o ato de sacrificar o órgão de uma pessoa com saúde que este seja um ato completamente consciente e responsável por todos os envolvidos.

A primeira tarefa, talvez a mais difícil, para o psicólogo, é responder a pergunta sobre o caráter da motivação para o transplante do potencial doador, pois cria um espaço propício para diversas reações psicológicas do doador, do receptor e da família, devido à situação de falta de órgãos cadavéricos ou à demora na lista de espera para 0 transplante. Entretanto, para dar continuidade ao processo de transplante com a devida responsabilidade que 0 assunto merece, é mesmo necessário investigar por que alguém sacrifica parte de seu órgão vital, expondo a si mesmo a um procedimento diagnóstico complexo e a uma cirurgia arriscada. As respostas para esta inquietação requerem a avaliação das características psicológicas do doador e do receptor, os vínculos emocionais ou a existência de outro tipo de relação entre eles, a posição deles na família e as características básicas da rede de relações familiares. Os costumes e sistemas de valores familiares estão incorporados nas características socioeconômicas e socioculturais do ambiente do qual a família pertence e, dependendo das especificidades da cultura e tradição, as atitudes para doar um órgão com o doador ainda vivo será diferente (Jones et al., 1993). 
Transplantes de órgãos:avaliação psicológica

As transformações das relações emocionais que permeiam todo o procedimento de transplante são causadas pela imprevisibilidade da dinâmica das relações existentes e dificilmente podem ser diagnosticados por meio de protocolos clássicos. Considera-se como meio de alcançar este objetivo as entrevistas psicológicas, por meio da escuta clínica voltada para as determinações inconscientes deste querer de doação.

Para entender a relação atual estabelecida no ambiente familiar é necessário saber sua dinâmica interna, suas características e modelos de funcionamento. Os membros da família do paciente estão em um estado ansioso específico, carregado com dilemas e frustrações que são constituídas em ambos os níveis, consciente e inconsciente, e são manifestados por vários comportamentos. No entanto, neste momento, muito pouco podem ser elaborados, pois a grande preocupação e motivação estão em salvar a vida do parente adoecendo. Sentimento de culpa, pretensão em responsabilidade moral e agressividade são constantes seguindo uma a outra. Dentro da família, os conflitos são muito freqüentes, que enfatizam o desequilíbrio entre a voluntariedade e o acordo racional que, por meio de critérios de vida geral, escolhe o candidato à doação. O altruísmo do potencial doador é um a priori levado em conta para outorgar, sem uma análise mais profunda dos impulsos inconscientes que o estimulam ou o desestimulam a doar o órgão voluntariamente.

É muito raro que todos os membros da família tenham a "motivação para doação", assim a participação nas discussões familiares sobre 0 assunto são grandes e acompanhadas com inquietude. Raramente podemos falar sobre uma "pura motivação" para a doação voluntária de um órgão, na maioria dos casos há uma combinação de motivos e impulsos (Spital et al., 1986).

Os doadores muito raramente estão prontos para expressar suas dúvidas e sentimentos íntimos. A maioria dos doadores tende a tomar a decisão sobre doação de um órgão impulsivamente, sem consideração racional, sob influência de um forte afeto, freqüentemente até mesmo sem adquirir algum conhecimento preliminar sobre as sutilezas do procedimento.

$\mathrm{O}$ ato do transplante estabelece uma relação muito íntima e delicada entre o doador e 0 receptor nos quais o órgão transplantado se torna o símbolo de um laço íntimo e específico. Em seu desenvolvimento e manutenção existe um investimento psicológico mútuo (Simmons \& Andeson, 1982).

\section{Alguns efeitos pós-transplante no receptor}

O receptor, geralmente, sente-se como um devedor, carregado de sentimentos de culpa e é difícil para ele não atender a qualquer demanda do doador. Para ele, às vezes, é muito difícil distinguir o órgão doado do membro familiar que doou. Fantasias de alterações físicas e de características de personalidade provocadas pelo novo órgão não são raras (Lazzaretti, 2004). Sentimentos de rejuvenescimento por ter tido um doador jovem até medo de interferência na identidade sexual, nos casos de receber o órgão de uma pessoa do sexo oposto.

A evolução da relação é determinada pelo destino do enxerto e as capacidades psicológicas de ambos os participantes para perceber a dinâmica da relação deles realisticamente, reconhecer suas expectativas e frustrações e expressar verbalmente em uma discussão tolerante. Neste contexto, há também hipóteses sobre a existência de uma conexão direta entre a qualidade da emoção que evolui na ligação do receptor e do doador e as manifestações somáticas de aceitação ou rejeição do transplante (Walter et al., 2002). Um senso exagerado de responsabilidade e obrigação por parte do receptor e a necessidade emocional de um direito de propriedade sobre o presente doado do doador pode mudar a qualidade da relação e pode criar um vínculo hostil entre eles.

Em casos de transplante cadavérico, sentimento de culpa no receptor muitas vezes se faz presente e alguns referem terem adquiridos algumas características do doador por informação efetiva ou fantasias fabricadas. Em geral, quando o órgão é de um cadáver, a identidade do doador não é revelada. Este é um procedimento que vale para os dois lados, nem o receptor fica sabendo quem é o doador e nem a família do doador fica sabendo quem foi o receptor, esta é a condição para a doação, preservar a intimidade de ambos. Entretanto, se o receptor quiser saber e a família do doador tiver consentido a divulgação da identidade do doador, as informações poderão ser fornecidas. 
A mistura de sintomas de natureza orgânica e psicológica é característica de mudanças psicológicas em pacientes transplantados no período imediato e posterior do pós-cirúrgico. Livre do tratamento e do contato intensivo com a equipe médica, o paciente em sua "nova liberdade" sente-se inseguro e desprotegido, inundado pela relação ambivalente frente as suas novas habilidades e seus velhos desejos. No período pós-cirúrgico imediato, o medo da rejeição do órgão paira sobre toda ação que ele faz e determina o seu comportamento, seu humor e restringe suas atividades. Com o tempo, 0 medo é diluído gradualmente e deixa de estar focalizado na possibilidade da morte.

O funcionamento do órgão transplantado traz uma melhoria global em qualidade de vida a nível físico e psicológico. A vida pode voltar a ser organizada com maior liberdade e autonomia, os pacientes podem readquirir a liberdade de fazer planos futuros.

Em alguns pacientes, a doença pode ferir o seu narcisismo profundamente, assim 0 transplante é imaginariamente visto como a restauração de saúde total e a perda definitiva do estado de paciente. A demonstração exagerada de "saúde restabelecida" pode conduzir os pacientes em promiscuidade, abuso de várias substâncias, principalmente o álco ol, e a evitação do acompanhamento terapêutico, médico, psicoterápico e outros.

\section{Considera ções finais}

O transplante como um método terapêutico não tradicional traz uma série de problemas psicológicos, sociais, legais e filosóficos. Considerando as implicações psicossociais significantes em todas as suas fases, este método mostrou a necessidade de um psicólogo como membro da equipe multidisciplinar (Cortesini, 1993). A contribuição do psicólogo clínico é introduzir e respeitar a dimensão subjetiva do paciente durante todo o processo de transplante.

O protocolo de avaliação psicológica prétransplante de órgãos sólidos utilizado no Hospital de Clínicas da UFPR foi elaborado a partir dos critérios considerados importantes para o restabelecimento psicossocial no pós-transplante, visando a uma compreensão dos recursos disponíveis do receptor e o doador para a elaboração e aceitação das circunstâncias psicossociais do percurso do transplante.

Em conclusão, o papel do psicólogo é muito delicado, especialmente nos casos de TIV, onde um doador compatível sacrifica um órgão saudável seu para contribuir com a saúde do paciente. O psicólogo clínico oferece uma escuta e trata as condições psicopatológicas com a idéia básica de possibilitar ao paciente um lugar para falar e se possível elaborar a situação que a doença lhe submeteu, dando significado à existência dele apesar de significantes limitações. Para que isto seja feito, o psicólogo clínico tem que restringir qualquer intenção de oferecer esperanças irreais e opções ao paciente, mas que ele possa saber o que deseja e espera de um transplante. 


\section{Referências}

Bonomini V. (1991). Ethical aspects of living donation. Transplant Proc. (23), 2497-2499.

Cohen C., \& Benjamin M. (1991). Alcoholics and liver transplantation. JAMA, (265), 1299-1301.

Cortesini R. (1993). Medical and ethical aspects of living donation. Transplant Proc. (25), 23052306.

Dew Ma, Roth L, Schulberg H, Simmons R, Kormos R, Trzepacz P. et al. (1996). Prevalence and predictors of depression and anxiety-related disorders during the year after heart transplantation. Gen Hosp Psychiatry, (18), 48S-61S.

Dew Ma, Switzer, G., \& Dimartini A. (1998). Psychiatric morbidity and organ transplantation. Curr Opin Psychiatry. (11), 621-626.

Jones J, Payne W., \& Matas A. (1993). The living donosr: risks, benefits and related concerns. Transplant Rev. (7), 115-128.

Lazzaretti (2004). Insuficiência renal crônica: da diálise ao transplante renal, uma reconstrução subjetiva. In Scortegna, S \& Bernincá, C. (org). Interfaces da Psicologia com a Saúde. Passo Fundo: UPF.
Walter M., Hildebrant J., Ruter J., Pascher P., Neuhaus, G., Danzer \& Klapp. (2002). Evidence of Psychosocial Influences on Acute Rejection After Liver Transplantation. Transplantation Proceedings, (34), 98-3301.

Simmons R.G., \& Andeson C. R. (1982). Related donors and recipients:five to nine years posttransplant. Transplant Proc. (14), 9-12.

Skotzko, Stowe, J. A., Wright, C., Kendall, K., \& Dew M. A. (2001). Approaching a consensus: psychosocial support services for solid organ transplantation programs. Prog Transplant. (11), 163-168.

Spital, A., Spital, M., \& Spital R. (1986). The living kidney donor: alive and well. Arch Intern Med. (146), 1993-1996.

Surman, O. S., \& Cisomi, A. B. (1996). Ethical dichotomies in organ transplantation: a time for bridge building. Gen Hosp Psychiatry, (18), 13-19.

Recebido em/received in: 22/11/05 Aprovado em/approved in: 23/02/06 


\section{Anexo I}

HO SPITAL DE CLIIN ICAS UNIVERSIDADE FEDERALDO PARANÁ

\section{Serviço de Psicologia}

\section{Breve Relatório da Avaliação Psicológica do R E C EP TO R}

\section{Psicóloga: Claire Terezinha Lazzaretti CRP 08/2440}

N. . Prontuário:

Data:

Nome:

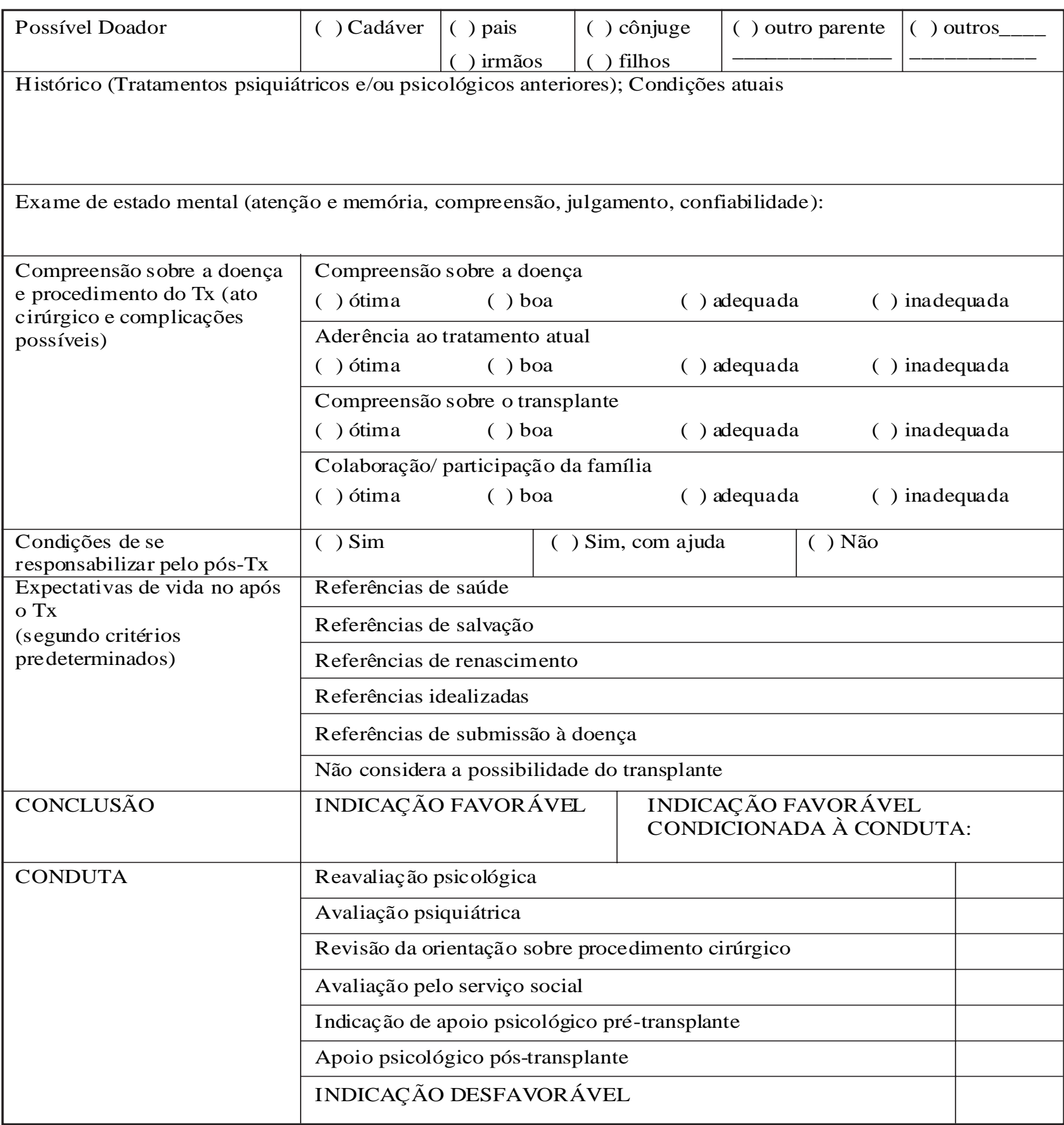




\section{Anexo II}

\section{Serviço de Psicologia}

\section{Breve Relatório da Avaliação Psicológica do DO A DO R}

\section{Psicóloga: Claire Terezinha Lazzaretti CRP 08/2440}

N. ${ }^{\circ}$ Prontuário:

Data: l 1

Nome:

Nome do Receptor:

\begin{tabular}{|l|l|l|l|l|}
\hline $\begin{array}{l}\text { Grau de parentesco ou } \\
\text { relacionamento com o } \\
\text { receptor }\end{array}$ & $\begin{array}{l}\text { ( ) pais } \\
\text { ( ) irmãos }\end{array}$ & $\begin{array}{l}\text { ( ) cônjuge } \\
\text { ( ) filhos }\end{array}$ & ( ) outro parente & ( ) outros \\
\hline
\end{tabular}

Histórico (Tratamentos psiquiátricos e/ou psicológicos anteriores); Condições atuais

Exame de estado mental (atenção e memória, compreensão, julgamento, confiabilidade):

Compreensão sobre o procedimento de doação (ato cirúrgico e complicações possíveis) Compreensão do procedimento

\begin{tabular}{l|l|l|l} 
( ) ótima & ( ) boa & ( ) adequada & ( ) inadequada
\end{tabular}

\begin{tabular}{l|l|l|l} 
Colaboração do doador & ( ) adequada & ( ) inadequada \\
( ) ótima & ( ) boa & ( )
\end{tabular}
Colaboração/ participação da família do doador

\begin{tabular}{l|l|l|l} 
( ) ótima & ( ) boa & ( ) adequada & ( ) inadequada
\end{tabular}

Razões para doação (s egundo critérios predeterminados)

Referências de altruísmo

Dever Moral

Retribuição

Outra razão:

Observações:

\begin{tabular}{|l|l|l|}
\hline CONCLUSÃO & INDICAÇÃO FAVORÁVEL & \multicolumn{1}{|l|}{$\begin{array}{l}\text { INDICAÇÃO FAVORÁVEL } \\
\text { CONDICIONADA À CONDUTA: }\end{array}$} \\
\hline \multirow{5}{*}{ CONDUTA } & Reavaliação psicológica & \\
\cline { 2 - 4 } & Avaliação psiquiátrica & \\
\cline { 2 - 4 } & Revisão da orientação sobre procedimento cirúrgico & \\
\cline { 2 - 4 } & Avaliação pelo serviço social & \\
\hline
\end{tabular}

